\title{
O memorial de aires e a libertação pela arte
}

\begin{abstract}
Resumo: Propõe-se um estudo do Memorial de Aires, de Machado de Assis, sob a perspectiva de sua estrutura musical. Se a questão da dor e da impossibilidade de o homem habitar o tempo e a história sem se dilacerar na contradição e na irrealização está proposta nesse romance, a questão recebe nele o seu enfoque decisivo, propiciado por uma aproximação com a filosofia de Pascal e de Schopenhauer. Do mesmo modo, não se pode afirmar que Machado de Assis professe abertamente uma filosofia da queda ou da vontade, a arte aparece como via de libertação, falando por meio do relato e das articulações sutis que se percebem no plano das imagens, bem como no recorte do seu formato musical. Nesse recorte, as instâncias do múltiplo e do uno se encontram e se entrelaçam, formando um todo que é, de certo modo, aberto e oferece um reflexo do mundo e suas contradições.

Palavras-chave: Romance brasileiro; Estrutura musical; Pessimismo; Memorial de Aires; Machado de Assis.

Abstract. Machado de Assis' Memorial de Aires is considered under the perspective of its musical structure. If this novel proposes the issue of pain and man's impossibility of inhabiting time and history without crashing in contradiction and emptiness, this issue receives a decisive approach, provided by an approximation with the philosophy of Pascal and Schopenhauer. Therefore, one cannot affirm that Machado de Assis professes a philosophy of fall or desire, since the work of art becomes a means of liberation, speaking through the plot and in the subtle joints that pervade the level of the images, as well as in the pure shaping of its musical format. In this format, the instances of the multiple and the unique mingle with one another producing a continuous whole that is to a certain extent open and offering a reflection of the world and its contradictions.
\end{abstract}

Keywords. Brazilian novel; Musical structure; Pessimism; Memorial de Aires; Machado de Assis.

\section{No limiar da filosofia}

Admitida a premissa de que uma inspiração de origem musical ${ }^{1}-$ baseada na forma sonata - perpassa o movimento de escrita que conduz o Memorial de Aires, resta-nos entender de que maneira esse fato responde a certas indagações suscitadas pela leitura da obra romanesca de Machado de Assis - indagações que, se as supusermos como próprias do universo ficcional do romancista, encontrariam nesse último livro o seu limite e a sua mais nítida

\footnotetext{
"Doutor em Letras. Universidade Federal da Grande Dourados - UFGD. E-mail: renatosuttana@ufgd. edu.br

${ }^{1}$ Este ensaio tem seu ponto de partida nas aulas ministradas pelo professor Wilton Cardoso no curso de mestrado da Pontifícia Universidade Católica de Minas Gerais, no primeiro semestre de 1994. Outras reflexões de Cardoso podem ser lidas em seu livro Tempo e memória em Machado de Assis (vide referências)
} 
inflexão. Trata-se, pois, de compreender a linguagem de apaziguamento em que se pode dizer que o romance é escrito, correspondendo esta, na medida do possível, às perquirições de ordem moral e filosófica que, na opinião de alguns, teriam sido as de Machado, em seu tempo, no campo da ficção - ligadas aos movimentos mais profundos de sua escrita. Se definirmos essas perquirições como pertinentes ao âmbito de uma filosofia da existência humana e do ser, então é preciso evocar as figuras de Pascal e de Schopenhauer, vistos como pródromos (principalmente este último) e anunciadores de uma compreensão da vida humana que se daria em uma pauta de caráter negativista, a constituir aquilo que, na história do pensamento moderno, veio a se denominar pessimismo filosófico.

Por certo, deve-se conceder, a princípio, que aplicar o rótulo de pessimista a um escritor é, de algum modo, impor determinado caminho de interpretação, o qual - se estamos mesmo a falar de influxos provenientes da filosofia - pode não fazer jus ao que supomos ser a sua singularidade e a originalidade da sua criação no universo do romance brasileiro e internacional. Assim, Machado não poderia ser compreendido - para estabelecermos os limites desta investigação - como um autor propriamente pessimista, pelo menos no sentido consagrado do termo, designação que seria contestada também por algumas interpretações mais contemporâneas de sua obra. Entretanto, arriscando ao menos uma aproximação - e assumindo que, no plano das ideias (provenientes da filosofia), existiria uma aproximação entre o romancista e o pessimismo -, seria justo dizer que, para Machado de Assis, uma reflexão acerca do existir que se debruça sobre o sofrimento em si, percebendo-o como inerente à existência humana, com os seus desencontros e contradições, mantém relações com o ato de escrever. A existência, olhada a partir do que seria a sua opacidade fundamental (que é ao mesmo tempo problemática e fragmentária), só encontra repouso no momento em que o homem se despoja, no instante em que, depondo o fardo das suas ambições e dos seus projetos e seguindo os passos ensaiados pelo Conselheiro Aires, converte-se em espectador, muitas vezes comovido, mas ao mesmo tempo isento e pouco participante, do fluxo ininterrupto das coisas. Esse deixar ser, essa efetiva recusa em participar (que poderia desbordar para o quietismo, mas que, supomos, tem alguma coisa de um recuo para o espaço da reflexão, no qual se movimenta o ato de escrita) - tudo isso reconduz o homem a si próprio, recolocando-o de frente para os limites e as contradições do seu viver. Porém, ao mesmo tempo, abre-lhe a possibilidade de transcender - conforme o termo que comumente se utiliza na 
filosofia -, por uma via que passa pelo processo da arte, o revezamento incessante de desejos, angústias, alegrias e decepções que constitui o fluxo da vida.

Uma reflexão pioneira sobre as relações de Machado de Assis com a filosofia pessimista foi esboçada por Afrânio Coutinho já nos anos 1940. Em seu estudo, Coutinho (1990, p. 111s.) tentou mostrar - em um esforço que talvez peque por não fugir a certa tendência à generalização - o influxo de Pascal e Montaigne sobre o que imaginamos ser, com o risco de nos vermos aprisionados em um círculo, o pensamento propriamente dito do romancista brasileiro. Se atribuirmos a Pascal um movimento de ideias que vai das percepções referentes ao homem decaído (e das angústias inerentes à queda) até a possibilidade de uma qualquer redenção pela confiança e pela entrega irrestrita aos poderes da graça, da qual promana uma nesga de luz que, no absoluto, brilha com a intensidade da certeza, teremos de admitir também, conforme já o entrevira Coutinho, que tal movimento apenas tangencia a obra do ficcionista brasileiro, uma vez que, neste último, a possibilidade do religioso (percutida no pensamento de Pascal) se encontra bloqueada ou é apenas acessória, episódica, sem marcar nenhum vértice significativo em sua produção.

Quanto à influência de Montaigne, foi Miguel Reale (1982, p. 10) quem alertou para a necessidade de, aqui também, olhar com cuidado, já que, na concepção do comentarista, embora não se possa negar tal influência, não é possível dizer que Machado tenha sido um "cético" no sentido estrito do termo, mesmo tendo alimentado desconfianças em relação aos sonhos do absoluto. Sua conhecida ironia, para mencionarmos apenas um dado, seria a prova do que se está a dizer. Mas, neste ponto, há que não ultrapassar a linha que separa o ceticismo real do niilismo profundo ou que distingue a dúvida sincera da superficialidade leve, esvoaçante e autocentrada do dândi. Em Machado pode-se dizer, minimamente, que o interesse pelo drama humano, expresso na forma do romance, contrabalança o perigo dos extremismos.

Outra presença que não se poderia ignorar e à qual Afrânio Coutinho se refere de passagem em seu ensaio seria aquela, mais evidente, de Arthur Schopenhauer. Mas, quanto a esta, deve-se atentar mais uma vez para o risco de atribuir ao autor do Memorial de Aires uma característica que talvez não lhe pertença, considerando-o, estritamente, como um adepto tardio da filosofia da vontade de Schopenhauer. Este aspecto, difícil de deslindar em sua profundidade (porquanto se poderia aduzir, em reforço, que não existe em Machado de Assis uma atitude filosófica declarada diante do mundo), foi 
com justiça entrevisto por Coutinho. E também não seria, como o salientou Reale, o caso de supor que Machado de Assis - romancista cujas reflexões sobre a arte e sobre a vida se teriam desenvolvido, em grande medida, pelo trilhar de caminhos próprios, sem provirem necessariamente de uma leitura dos filósofos - tenha escrito seus melhores romances à sombra de quem quer que fosse (bem como, muito menos, para ilustrar teorias). Assim, mesmo confrontados com uma experiência de mundo que não deixa de levar em conta o seu lado "demoníaco" - para usar esta expressão, isto é, a concepção de que o mal é inseparável da natureza das coisas -, não se encontrará em Machado uma explicação do mundo que se possa fundar no conceito da vontade, como acontece em Schopenhauer. Mostrou-o parcialmente Reale, em um comentário à crônica "Schopenhauer e o autor de si mesmo", publicada em A Semana no dia 16 de junho de 1895 . Não se trataria, ali, segundo o comentarista, senão de uma polêmica, que Machado conduz à sua maneira, travada contra o filósofo de Dantzig, na qual se revelam as contradições inerentes à doutrina da vontade.

Mas teria Machado, apesar dessa diatribe, ficado imune ao poder de atração do filósofo alemão, principalmente às seduções de sua escrita magistral (que tanto atraiu outros escritores)? Em certa medida, é justo dizer que, para Schopenhauer, o mundo, compreendido como representação de uma vontade que é, para o sujeito reflexivo, a manifestação do fundamento único e último da realidade, apresenta-se, sobretudo, como um mundo de aparências. E, como tal, torna-se também uma fonte de enganos e decepções, já que, imerso nelas, homem se vê sujeito ao despotismo da vontade, que o constringe de todos os lados, sem cessar, e o leva em direção a um querer insaciável cuja medida mais positiva seria, paradoxalmente, o sofrimento, na concepção de Schopenhauer. Não obstante, mergulhando em si mesmo, o homem acaba por se perceber como sujeito, o lugar onde a vontade se torna consciente de si própria, objetivando-se com razoável transparência nas formas positivas que o sujeito percebe em sua experiência do mundo. Disso emana a possibilidade da contemplação (das ideias puras), na qual ele mesmo - o sujeito cognoscente - consegue, aos poucos, furtar-se ao movimento da vontade e ao seu poder de arrasto. Assim, vontade que se (auto)contempla, sua meta aponta para o nada, para a anulação de si próprio pela contemplação, que leva à supressão do querer e abre o caminho para a libertação.

A vontade, para o pensador alemão, seria intraduzível, livre e atemporal. Por ser assim, ela só se apazigua na medida em que se contempla, em que percebe que não almeja senão a si mesma; ou seja, que outra coisa não quer 
senão anular-se no nada. A operação que leva à supressão do "querer viver" seria, então, para alguns, a autorrenúncia sustentada pela ascese. Entretanto, como nem todos os homens são capazes de alcançá-la ou desejam, minimamente, a sua consecução, conclui-se, com Schopenhauer, que a essência do mundo, decorrente do modo de ser da vontade, não é outra coisa que a dor $\mathrm{e}$ o sofrimento, palavras que frequentam os livros do filósofo. E não existe no mundo outra via que conduza à superação do "querer"? Talvez exista, mas, para vislumbrá-la, é preciso começar pela compreensão de que, tomada como fundamento, a vontade não se dá a conhecer senão por meio da intuição. Esta, que dá acesso ao fundamento, é a intuição das ideias supremas, realizadas no mundo como representações ou objetivações da vontade. A arte, nessa contextura, é aquela que permite ao homem um puro contemplar, o qual se traduz na possibilidade de vislumbrá-las, de exprimi-las (com recurso ao gênio criador) mediante as obras em que as ideias puras se deixam entrever. Na arte, o homem se alça aos domínios superiores da compreensão - que são, também, domínios superiores de experiência -, reconhecendo, por meios diversos, que a dimensão fundamental de sua existência é o não desejar. Desse modo, já não mais desejando, ou não tendo mais o que desejar (a arte não apresenta, sob esta perspectiva, nenhuma utilidade prática e não está sujeita ao fluxo da causalidade), não mais deseja, por sua vez, o mundo e seus fenômenos.

É interessante observar que, em Schopenhauer, bem como em boa parte da filosofia oriunda do idealismo alemão dos séculos XVIII e XIX, tornam-se marcantes as distinções entre forma e fenômeno, entre permanência e fugacidade, ou entre unidade e multiplicidade. Com referência à música, por exemplo, Schopenhauer dirá que esta não é senão a forma suprema da arte. Em um sistema de hierarquias, cuja postulação se baseia na noção de utilidade - isto é, que ascende da mais útil (a arquitetura) à menos útil (a música) -, a atividade musical ocuparia o topo da cadeia, pois outra coisa não é que a própria revelação da vontade a si mesma, objetivando-se até o limite da saturação. Segundo o filósofo, compor a música é atingir a intimidade do fundamento, sendo o compositor aquele que se revela capaz de exprimir, "numa linguagem que desconhecemos, a quinta-essência do mundo e a mais profunda sabedoria" (SCHOPENHAUER, 19--, p. 112). A inutilidade da vida transborda e se torna patente; mas a música, libertando-se das amarras que nos prendem ao jogo infinito das metas e dos propósitos que só conduzem ao desespero, tem o poder de transcendê-los: 
Dominado por seus desejos, o homem está continuamente preso à roda de Ixion, enche sempre o tonel das Danaides, é o Tântalo devorado de eterna sede. $[\ldots]$

Mas, quando uma causa estranha ou a nossa harmonia interior nos arrebata à torrente infinita do desejo, livra-nos o espírito da opressão da vontade, desvia-nos a atenção de tudo que a solicita; é então que contemplamos tudo sem interesse ou cobiça. (SCHOPENHAUER, 19--, p.112-19)

"A música em geral é a melodia, cujo texto é o mundo" (SCHOPENHAUER, 19--, p. 119), escreve o autor. De todas as formas de composição musical, a mais inferior seria, justamente, a ópera, porque privilegia, em detrimento da "linguagem universal", a multiplicidade dos fenômenos exteriores, na forma dos recursos técnicos exigidos pelo espetáculo (encenação, cenografia, enredo), os quais só podem visar à inteligência, mas não às profundidades últimas da intuição. Desvia-se, pois, de sua meta, que é atingir e operar diretamente sobre o espírito, fazendo uso, no desvio, de um instrumental que só diz respeito às contingências - e que não remete, portanto, ao essencial ou a um saber que poria a nu as dissimulações.

O mesmo se aplicaria, no campo da literatura, ao movimento da narrativa: quanto mais a obra se perde, pela sua própria maneira de se constituir, no exterior das manifestações fenomênicas, tanto menos se aproximará desse fundo. Na concepção de Schopenhauer, "uma novela será tanto mais elevada e nobre quanto mais vida interior e menos exterior representa". $\mathrm{Na}$ ordem do mesmo raciocínio - ou seja, na perspectiva (que se renova a cada vez e ao mesmo tempo nos escapa) de uma eterna oposição entre o essencial e o acessório -, "a arte consiste em que com a menor quantidade possível de vida exterior se ponha no mais forte movimento a interior, porque a interior é verdadeiramente objeto de nosso interesse" (SCHOPENHAUER, 1941, p. 41).

A narrativa se exprime, portanto, pela voz da multiplicidade. Mas, ao mesmo tempo, "esconde" uma essência íntima que a torna arte antes de tudo, bem como espelho (potencial) da vontade que se objetiva - espelho que adquirirá maior nitidez na medida em que a obra se desnude em si própria, quer dizer, na medida em que, acometida pela ascese, deitando fora os atavios e o apego à exterioridade, abra uma senda que permitirá o acesso pleno ao fundamento da experiência ou, mais propriamente, à experiência fundamental. 


\section{Música de imagens}

Seria possível falar do Memorial de Aires tomando como ponto de partida a sua "simplicidade" ou considerando-o como um livro em que, em relação aos outros escritos de Machado de Assis (ou da sua época), a narrativa mais se desnudou e se despojou do acessório e do superficial? Mas não estaria o despojamento a ocultar tensões e conflitos internos, reveláveis somente a uma leitura que, despojando-se também, viesse a se propor a uma audição desarmada, disposta a ouvir aquilo que só a linguagem do desnudamento é capaz de dizer? Em seu livro sobre a manifestação da filosofia na obra de Machado de Assis, Afrânio Coutinho tratou o Memorial, sugerindo que, nele, realizar-se-ia, do ponto de vista do pensar filosófico, uma espécie de "transfiguração" da visão de mundo do romancista. O romance proporia não tanto um aprofundamento, mas uma transposição, na qual o que veio se construindo ao longo de toda a obra alcançaria um ponto de transformação ou um limite.

Entretanto, se nos filiarmos à tese, teremos de admitir a ideia de que, na obra, essa visão de mundo tenderia a um pessimismo radical, o qual se tomaria como pressuposto da abordagem da assim chamada produção madura do romancista, pessimismo que, ainda no entender de Coutinho (1990, p. 228), reconciliar-se-ia mais tarde com o mundo, no sentido de uma "humanização", isto é, de um gesto que, por último, seria capaz de transfigurar a existência. Mas o que indica o verbo transfigurar, senão que neste ponto se está a estreitar o caminho, restringindo-se o alcance da interpretação ao se desconsiderar o elemento de abertura que deveria aparecer como o ponto para o qual tende a narrativa, na medida em que aprofunda seus impasses, elemento este identificado, como o teria entendido Bakhtin (1993, p. 107-33), com a noção da multiplicidade.

Sem entrarmos em considerações quanto ao problema - e para nos limitarmos ao escopo deste trabalho -, temos de avaliar dois aspectos que, a nosso ver, sobressaem da leitura do Memorial de Aires quando o perquirimos sob o ponto de vista de suas motivações mais profundas. O primeiro aspecto se refere à suprarreferida ideia da multiplicidade, à qual aplicaríamos o conceito de Bakhtin. Podemos perguntar: de que maneira o escritor, elaborando uma narrativa cujo sinal mais exterior é a suposta nudez de adereços, seu despojamento essencial - patente, por exemplo, na ausência de um enredo propriamente "romanesco" (no sentido de que lhe faltariam os grandes lances dramáticos 
que caracterizam os romances chamados "de ação") -, alcança, mesmo assim, realizar no romance uma espécie de polifonia, para usarmos o termo da teoria musical, ou de concerto de vozes que, a seu tempo, possibilitaria o afloramento do múltiplo, sem no entanto trair o despojamento? Dois vetores parecem surgir. Primeiramente, se lançarmos o olhar para a posição sui generis desse narrador particular, perceberemos que o seu modo de relacionar-se com os fatos que descreve é o modo do observador mais ou menos imparcial, o qual, ao mesmo tempo, vê a si mesmo imerso no fluxo e com ele comprometido. Exterior e interior aos eventos que relata, o Conselheiro Aires, conforme já se observou mais de uma vez, não apenas narra uma história cujo conteúdo lhe seja de antemão conhecido ou que ele "domine" por força dos privilégios que lhe concedem a sua posição (de narrador) ou o caráter impositivo da lembrança. Antes, ele mesmo se deixa narrar pelo que conta, e o faz a tal ponto que os acontecimentos à sua volta parecem tomar corpo em um tempo não instituído pelo narrar (o que, em outra circunstância, seria o caso para uma narrativa que se declarasse desde o início como pura ficção), mas, antes - conforme observou outro crítico ${ }^{2}$ - fundado na sua própria temporalidade, que o suceder dos eventos, instável, aberto às incertezas do acaso, abre também às interpretações do leitor e do narrador. Poderia haver coincidência entre essas duas ordens de interpretação?

Se Aires é a única voz que se ouve no relato e se o seu domínio sobre o nível da exposição dos fatos obriga a que todas as outras vozes lhe estejam de certo modo subordinadas, nem por isso se pode dizer que as vozes não estejam lá, ao seu modo, abrindo poros pelos quais a ambiguidade penetra na linguagem do romance. Não haveria, portanto, até onde podemos ver, um núcleo central ou a possibilidade de um centramento, a fundar uma visada "onisciente" do que se narra, mas brotaria, de todos os lados, uma diversidade de falares (sendo o próprio narrador uma figura periférica, que nada pode garantir acerca do que diz e nada pode relatar a não ser o que ele mesmo presencia - que, por sinal, não é muito - e, sem ultrapassar o limite, interpreta) que põem em questão a

\footnotetext{
${ }^{2}$ Quanto ao problema do narrador no Memorial de Aires, Ivan Junqueira escreveu: "Diante de seu memorial estamos, como na vida, em absoluta igualdade de condições. Não vale a subordinação do espírito, mas a justaposição. Ele ambiciona o real sem cabrestos." (JUNQUEIRA, 1987, p. 163) E, quanto à criação de uma personagem central, no caso, Tristão: "De fato, a caracterização de Tristão terá, por força, de decorrer do confronto entre as opiniões que dele têm as pessoas de seu convívio. O narrador é uma delas. A criação dessa dinâmica para se apurar, num romance, o caráter de uma pessoa revela um surpreendente refinamento ético-literário, do qual haverá porventura poucos exemplos na literatura universal." (JUNQUEIRA, 1987, p. 163) 
fala única. Por outras palavras, pode-se pensar que exista ali, acompanhando o Conselheiro (que, aliás, muito mais ouve do que vê), uma pluralidade de narradores ou de falares, e que isto seria, para os efeitos desta abordagem, a primeira prova a caracterizar a multiplicidade a que nos referimos.

Outro traço - o segundo - a sugerir a ideia de que uma inspiração musical subjaz ao movimento da narrativa, a sustentá-la como um fundo, manifestar-se-ia como uma canalização das forças dispersivas do primeiro aspecto. Como o sugeriu Wilton Cardoso (1958), o Memorial de Aires seria um romance em que se desenvolvem dois temas, entrelaçando-se em vários pontos, mas ao mesmo tempo progredindo por caminhos distintos, tal como se dá na música com a forma sonata. Esses temas seriam anunciados em uma breve exposição, que cobriria os primeiros registros do diário. Igualmente, não é difícil imaginar que a narrativa se desdobre em três partes, também como na forma sonata, cada qual apresentando um andamento específico. Não reproduziremos aqui, em sua inteireza, todo o movimento da análise. Contenta-nos aventar a ideia de que, neste particular, o fluxo da narrativa, qualquer que seja o seu curso, obedece a três movimentos, que podem ser descritos da seguinte maneira:

1) os grandes blocos de informações, os intervalos de tempo mais largos, o ritmo ágil do relato, a marcar os registros que vão do início do romance até o dia 17 de junho (de 1888), que constituiriam o allegro inicial;

2) o ritmo pausado, o detalhamento descritivo, os acontecimentos narrados em minúcias, acompanhados de perto pelo Conselheiro, que surgem nos registros subsequentes e se estendem até o dia 28 de dezembro, insinuando o andamento lento e os ritmos pausados de um adagio; $\mathrm{e}$

3) finalmente, os registros em ritmo (novamente) ligeiro, dançante, pintados com pinceladas rápidas, produzindo a impressão de que a narrativa se precipita para o desfecho, o que constituiria o minueto final.

Por sua vez, as variações resultantes das múltiplas interseções entre os dois temas indigitariam um segundo aspecto da referida multiplicidade. Ao concentrar o que se vai dispersando, dado o número de coadjuvantes cujas "vozes" fornecem ao Conselheiro a matéria-prima de seu relato, elas imprimem 
unidade ao enredo - um tipo, evidentemente, problemático de unidade, que teria sua origem em um dualismo. Esses temas seriam o da velhice solitária, com sua necessidade de amparo, proteção e afeto, e o da juventude que desabrocha, buscando seguir os seus próprios caminhos. Desenvolvendo-se ao longo do relato como em uma peça musical, deverão ambos confluir para um inexorável confronto no final. Sabemos como se dá o confronto: o jovem Tristão, "filho adotivo" e celebrado do casal Aguiar, retorna da Europa e lhes arrebata a viúva Fidélia, também ela "adotada" como filha pelos velhos. De certo modo, nesta altura, é como se o segundo tema - o da juventude - prevalecesse sobre o primeiro, e aqui nos aproximamos mais uma vez da forma sonata.

A aceitação de tal possibilidade de interpretação dependerá, portanto, de que percebamos e levemos em conta os cruzamentos de temas. O elemento musical aflorará, significando que, caso o rejeitemos e caso não demos ouvidos à possibilidade de ler o romance com o apoio dos pressupostos da filosofia de Schopenhauer, teremos de enfrentar o risco da pura negatividade, como se o escritor tivesse se esforçado para tornar visível, no final, o puro sofrimento, resultante do abandono dos velhos pelos recém-casados. Mas, então, poderíamos perguntar se uma coisa não compensa a outra, e se não existe um equilíbrio, derivado do fato de a vitória da juventude compensar o mergulho dos velhos na solidão, por mais estranho que isso possa soar. Para Schopenhauer, a continuidade da espécie, a sobrevivência da vontade nas formas imutáveis contrabalança a angústia do desaparecimento dos indivíduos. E o mesmo se daria no plano da música:

\begin{abstract}
A passagem duma tonalidade diferente, que quebra qualquer ligação com a tonalidade precedente, assemelha-se à morte na medida em que ela destrói o indivíduo; mas a vontade que se manifesta nele continua a viver e manifestar-se noutros indivíduos, cuja consciência contudo não continua a do primeiro. (SCHOPENHAUER, 19--, p. 345)
\end{abstract}

A pergunta, contudo, corre o risco de parecer infundada, uma vez que também se poderia argumentar que a hipótese (da negatividade) não dispõe de suficiente relevância, em virtude até da própria abertura de interpretação que a forma do romance propicia. Ou seja, pode-se dizer que a questão esbarra, sobretudo, na possibilidade de confrontar o romance com a realidade, e que não competiria ao autor solucioná-la, muito embora, ao constatá-la, 
seja-lhe possível dar a ela esse quê de poético que até certo ponto a ameniza. Seja como for, isso implicaria, caso recorramos novamente a Schopenhauer, admitirmos que, em um confronto entre a dor e o prazer, entre a frustração e a vitória, prevalece sempre a primeira alternativa, até porque, para o filósofo alemão, "só a dor é positiva", sendo o prazer nada mais que uma cessação, uma ausência de dor. Mas, a esta altura, seria preciso retornar ao elemento musical do romance, o qual, somando-se à multiplicidade, se poderia considerar como sendo o segundo fator importante para o exame da questão e para o complemento da interpretação.

A questão que nos colocávamos era: de que maneira o romance responde a certas indagações de ordem moral e filosófica de Machado de Assis acerca do sofrimento, e em que sentido, com o confronto dos temas mencionados - juventude e velhice -, poderia manifestar-se a possibilidade de uma conciliação (entre os temas), levando-se em conta a eventualidade de o Memorial representar o momento por assim dizer "nobre", apaziguado, no que diz respeito às respostas que a arte pode dar às nossas indagações acerca da existência, da obra do romancista?

A resposta parece insinuar-se na própria conjunção dos elementos, descritos, de modo esquemático, a partir do dualismo entre multiplicidade-exterioridade e musicalidade-interioridade. Há que admitir que o relato, que é também a obra de arte literária, projeção do real e no real, jogo infinito de vozes e imagens jamais estáveis, projeta, pelo seu modo de se constituir, o aspecto inconciliável da multiplicidade, e do puramente exterior, sobre o elemento pacificado e pacificador da música, entendido este último, como se viu, por Schopenhauer como via de libertação, aberta para o homem, em relação a um querer e a um querer viver cuja mordida o avassala. Assim, mais perto do essencial, o romance estaria em condições de se converter em espelho ou imagem da vida, na qual o desejo se mira e se liberta, espelho que nem por isso perderia as suas qualidades ambíguas, porquanto é ele mesmo, no fim, uma figura dual e controversa.

Quanto a isso, pode-se postular certa solidariedade entre os três elementos que aqui relacionamos, caminhando então do mais exterior para o mais interior e escalonando-os por pares. Em primeiro lugar, haveria o "concerto" de vozes, a dar suporte aos dois temas referidos, que se confrontam entre si. Em seguida, surgiria o confronto dos temas, constituindo, em movimento, os vários ritmos específicos da escritura musical. E por fim teríamos o "concerto" das 
vozes, múltiplo, dispersivo, a operar sobre uma estrutura unificada (a partitura musical), por via de sua redução aos dois temas, os quais se colocariam, assim, como elemento intermediário entre exterioridade e interioridade na arquitetura do romance. Esta interpretação, evidentemente, seria apenas aproximativa, uma vez que nenhum dos fatores poderia ser intuído sem a presença dos demais. E haveria, por fim, a presença do narrador, que, de certo modo, regula e articula as várias instâncias do relato, dando-lhes corpo na forma característica do diário, a qual garante a aproximação entre os ritmos da realidade exterior e os ritmos da narrativa (de modo que estes apontem para aqueles). A arte, enfim, referindo-se ao mundo, busca incessantemente as formas do mundo, até se tornar talvez, conforme o supunha Schopenhauer, o verdadeiro lenitivo para as angústias do sofrimento e da desagregação a que os homens estão condenados.

Se a questão da dor e da impossibilidade de o homem habitar o tempo e a história sem se dilacerar na contradição e na irrealização está proposta no último romance de Machado de Assis, pode-se pensar que ela, neste romance, recebe o seu enfoque mais decisivo, propiciado certamente por uma aproximação também decisiva com a filosofia. Como em Schopenhauer-e, no entanto, sem que possamos afirmar que se professe ali, abertamente, uma filosofia da vontade e sem que possamos afirmar que exista uma adesão final ao postulado filosófico -, o romancista vê na arte uma via de libertação. Para tanto, deixa falar o próprio relato, não diretamente, mas por meio das articulações mais sutis que se percebem no plano das imagens, no seu recorte puro e no seu formato musical, no qual as instâncias do múltiplo e do uno se encontram e se entrelaçam. Formariam, assim, um todo contínuo que é, de certo modo, aberto e que oferece, em si, um último reflexo do mundo.

Arte e mundo se encontram, numa complementação, o múltiplo a se projetar e a encontrar equilíbrio no musical, oferecendo, à maneira de uma catarse discreta, e para citarmos uma expressão de Rilke, "êxtase, consolo e amparo" aos homens cuja relação com a vida é desde sempre marcada pela procura daquilo que o real só oferece por lapsos, de modo descontínuo e, por isso mesmo, insatisfatório.

\section{Referências}

ASSIS, Machado de. Memorial de Aires. Rio de Janeiro/Brasília: Civilização Brasileira/ INL, 1977. (Edições críticas de obras de Machado de Assis, v. 10) 
O memorial de Aires e a libertação pela arte

BAKHTIN, Mikhail. Questões de literatura e de estética: a teoria do romance. 3. ed. São Paulo: Unesp, 1993.

CARDOSO, Wilton. Tempo e memória em Machado de Assis. Belo Horizonte: Itatiaia, 1958.

COUTINHO, Afrânio. A filosofia de Machado de Assis. In: Machado de Assis na literatura brasileira. Rio de Janeiro: Academia Brasileira de Letras, 1990, p. 109-225.

HIRSCHBERGER, Johannes. História da filosofia contemporânea. 2. ed. São Paulo: Herder, 1968.

MORA, José Ferrater. Diccionario de filosofía. Buenos Aires: Sudamericana, 1958.

REALE, Miguel. A filosofia na obra de Machado de Assis: com uma antologia filosófica de Machado de Assis. São Paulo: Pioneira, 1982.

SCHOPENHAUER, Arthur. O amor, as mulheres e a morte. São Paulo: Cultura Moderna, [1936].

Metafísica de lo bello. Buenos Aires: Editorial Tor, 1941.

O mundo como vontade e representação. Porto: Rés, [19--]. Livro 3.

TEIXEIRA, Ivan. Apresentação de Machado de Assis. São Paulo: Martins Fontes, 1987.

Recebido para publicação em 30 de junho de 2009. Aceito para publicação em 11 de março de 2010. 